\title{
Chemical Engineering Student Perceptions of Communication Development from Participation in Game-Based Activities
}

\begin{abstract}
Abigail Jane Kulhanek
Abigail Kulhanek is an undergraduate student studying Chemical Engineering at the University of Pittsburgh.

\section{Dr. Cheryl A Bodnar, Rowan University}

Cheryl A. Bodnar, Ph.D., CTDP is an Assistant Professor in the Department of Experiential Engineering Education at Rowan University. Dr. Bodnar's research interests relate to the incorporation of active learning techniques in undergraduate classes as well as integration of innovation and entrepreneurship into the engineering curriculum. In particular, she is interested in the impact that these tools can have on student perception of the classroom environment, motivation and learning outcomes. She obtained her certification as a Training and Development Professional (CTDP) from the Canadian Society for Training and Development (CSTD) in 2010, providing her with a solid background in instructional design, facilitation and evaluation. She was selected to participate in the National Academy of Engineering (NAE) Frontiers of Engineering Education Symposium in 2013 and awarded the American Society for Engineering Education Educational Research Methods Faculty Apprentice Award in 2014.
\end{abstract}




\title{
Chemical Engineering Student Perceptions of Communication Development from Participation in Game-Based Activities
}

\begin{abstract}
Workplace surveys show communication skills are essential to success in engineering practices; however, a large gap has been identified between workplace needs and engineering graduates' skills. A contributing factor to this could be that engineering programs rarely require students to take courses exclusively focused on developing skills in public speaking, presentation, or technical communication which in combination with students' attitudes that communication is not necessarily a key skill to engineering can exacerbate the problem. Despite efforts to increase the focus on communication in the engineering curriculum, recent engineering graduates entering the workplace are still reported to be deficient in written and oral communication skills.

This work investigates student perception of written and oral communication skills after their participation in game-based activities as a means to determine whether game-based pedagogy could serve as a potential tool to enhance these skills in engineering undergraduates. Game-based learning incorporates game design elements in non-game contexts, balancing subject matter and game play to help players engage in the information being presented, while allowing them to learn how to apply it in real world contexts, such as communication in industry.

Game-based communication activities were incorporated into one section of Introduction to Chemical Product Design including 86 chemical engineering undergraduates in the spring of 2015. Three different game-based communication activities were covered with the students. "Professional Slide" was a game-based activity where students acted as employees for a company in distress, explaining to customers in a single slide why a recall had been issued on their product. In the "ROYGBIV" game-based activity, students received cards with a code and had to describe the components of their cards with only oral communication in an attempt to decode their card and solve the class based problem. Finally, "Mystery Liquid" was a gamebased activity where students had to describe an unknown liquid to their team members based on appearance, smell and feel solely through written communication so their team could correctly identify the liquid without ever seeing it.
\end{abstract}

Reflection-based homework assignments were developed to obtain students' perception of these game-based communication activities as prior research showed that use of these game-based communication activities resulted in positive improvement in both students' oral and written communication skills. The coding scheme for the reflections was developed using a grounded, emergent qualitative analysis. The reflections were then content analyzed by two analysts. An inter-rater reliability measure based on Cohen's Kappa was calculated for each game-based activity. The inter-rater reliability for the "Professional Slide," "ROYGBIV," and "Mystery Liquid" game-based activities were calculated to be $0.641,0.647$, and 0.597 respectively, reflecting a fair level of agreement. Reflections were also analyzed to determine which themes were more prominent in each game-based activity, whether differences existed in these themes based on student gender, and what that meant for the students' perceptions of communication. For example, the top three themes for the "Professional Slide" game-based activity were \{approach - framing\}, \{audience perception - understanding/listening\}, and \{approach presentation . When looking at the differences between genders for this game-based activity, the 
top three themes for females were $\{$ approach - framing $\}$, \{ audience perception understanding/listening $\}$, and $\{$ approach - detail $\}$ and the top three themes for males were \{approach - detail \}, \{audience perception - understanding/listening, , and \{approach presentation $\}$. As can be seen by these top themes, there was little variation observed between male and female reflections on the game-based communication activities.

\section{Introduction}

In 1981, two walkways in the lobby of the Kansas City Hyatt Regency Hotel collapsed. In 1986, the Space Shuttle Challenger broke apart 73 seconds into flight. In 1999, the Mars Climate Orbiter entered too far into the Martian atmosphere and disintegrated. In 2003, the Space Shuttle Columbia disintegrated during re-entry after its $28^{\text {th }}$ mission. The collapsing walkways killed more than 100 people and injured approximately 200. ${ }^{1}$ Both Space Shuttle explosions killed crews of seven and the Mars orbiter explosion cost NASA \$125 million. ${ }^{1,2}$ These catastrophic events have one thing in common - miscommunication between engineers and other project members. In the hotel walkway disaster, a structural engineer submitted preliminary drawings that were taken to be final from the steel fabricator. ${ }^{1}$ Internal flight safety problems were bypassed and miscommunication between engineering and management foolishly launched a spacecraft based on incomplete and misleading information, causing the Space Shuttle explosions. ${ }^{1}$ The Mars orbiter disintegrated because of a mismatch in units between ground control and the actual spacecraft. ${ }^{3}$ When there is miscommunication between engineers and other individuals involved in projects, catastrophic events can occur. Many people can lose their lives and companies can lose significant amounts of money. These events reinforce the importance of communication within engineering.

Along with technical skills, students in the engineering discipline are expected to have proficient communication skills when entering industry. ${ }^{4}$ According to a survey of industry representatives, working engineers say they spend over half of their day communicating either through collaborating with other employees or discussing opportunities with customers. ${ }^{5}$ Writing, speaking, and drawing are not simply used for passing information along within engineering; these communication techniques are also used to generate and analyze knowledge. ${ }^{6}$ For example, a team of engineers are tasked with developing a new laptop computer for Lenovo; members of the team draw their designs on a whiteboard and explain the functionality while other members openly discuss if the designs are feasible, writing down features that are essential in the final design. Technical ideas such as a new laptop design and results from testing those ideas are not useful until and unless they are communicated and discussed. ${ }^{7}$ In a survey of recent graduates from the State University of New York at Buffalo, a respondent commented, "An engineer is only as good as his ability to communicate his ideas". 7 An Engineering Curriculum Task Force study rated effectiveness in communicating ideas as second in importance only to problem recognition and solution skills. In this survey, communication skills were rated more important than mathematics, science, and technical skills. ${ }^{8}$ Despite surveys ranking communication skills with high importance, engineering graduates are not meeting industry expectations for communication skills. ${ }^{7,9,10}$

In an interview with professionals describing the lack of communication skills within the engineering industry, a respondent stated, "[recent engineering graduates] communication skills are not good, they're less than not good, they're really bad. In most cases, they're not strong 
communicators and that is a problem because we are trying to get some of our technical people to participate in client presentations". ${ }^{4}$ Another survey response included, "There are a lot of very good technical minds in the workplace, but very few that communicate effectively". ${ }^{\text {In a }}$ survey of electrical engineers, $41 \%$ of respondents reported receiving employer-paid training in communication skills. ${ }^{5}$ This statistic indicates engineering companies are making investments to train their engineers in a skill in which engineering graduates should already be adequately trained upon graduation. The Society for Manufacturing Engineers named "lack of communication skills" among the top competency gaps in engineering education. ${ }^{7}$ As shown by these survey responses, communication skills are important in the engineering industry, yet engineering graduates are not meeting employer communication expectations. Engineering education has been making an effort to close this gap; however, an obvious separation between employer expectations and engineering graduates' skills still exists. ${ }^{7,8}$

\section{“Present Case: Communication in Engineering Education"}

The 1995 report from the National Board of Engineering Education includes recommendation for a redesign of the engineering curriculum toward a more professional focus with specific attention on instruction in communication. ${ }^{4}$ ABET is driven by eleven student outcome measurements, two of which state that students should graduate with an ability to communicate effectively and work productively on teams. ${ }^{4}$ To be accredited, a program must show their engineering curriculum meets these standards. Approaches to communication instruction in engineering can include requiring writing or communication courses, collaborating with communication and writing centers, or integrating communication and writing programs within standard engineering curricula. ${ }^{11}$ However, it is questionable if this is enough - will one mandatory communication class or collaborating with the writing center for one semester be sufficient in training engineers to have the communication skills employers anticipate? Regardless of pedagogical approach, engineering communication initiatives typically incorporate the teaching of context specific communication skills or communication in the disciplines, which may be too narrow according to Fleury. ${ }^{12}$

In 1987, a technical communication program that focused mainly on junior and senior students was initiated at the State University at Buffalo's School of Engineering and Applied Sciences. Their instruction combined several job-related features originated and proven in the workplace such as information models, quality control writing strategies, language guidelines, efficient teaching methods, and constructive feedback procedures. Their program included courses that aimed to address the main communication problems engineers, scientists, and students consistently identified in numerous questionnaires and classes along with enthusiastic support of an industrial advisory committee whose members mentored students one-on-one. ${ }^{7}$ This university worked directly with industry to train students in communication, however, not every student benefitted from the program as the school thought. After a couple years in industry, these students were asked to take a survey regarding their communication skills and how the program had impacted their workplace experiences. Because the communication courses in their program were electives and therefore not mandatory, students did not always enroll in these courses. One survey respondent commented, "I never took instruction in tech writing, but I wish I had. It is vital to me in my job". 7 Engineering students are realizing communication skills are important too late. Graduates only realize communication skills are a necessity after employment whereas employers anticipate proficient communication skills upon hiring. This late recognition could be 
caused by students perceiving communication as unimportant or misjudging their communication abilities. There may be a disconnect between undergraduate students' thoughts on the importance and difficulty of communication and its actual importance and difficulty in industry, or there may be a disconnect between students' perceived ability to communicate and their actual ability.

\section{Gender Influences on Communication}

To be effective, educational tools should appeal to both male and female students equally. Males are said to use language to enhance social dominance and achieve tangible outcomes while females are said to use communication to enhance social connections and create relationships. Females are more expressive, tentative, and polite with the language used while males are more powerful and assertive. ${ }^{13}$ According to John Gray, the author of Men are from Mars, Women are from Venus: a Practical Guide for Improving Communication and Getting What You Want in a Relationship, males and females have different needs, goals, and values in the way they communicate. Men are goal oriented and define their sense of self through their ability to achieve results while women are relationship oriented and define their sense of self by their feelings and quality of relationships. ${ }^{14}$ Males prefer inequality and asymmetry and value difference between individuals - where competition sets a winner apart from everyone else. Females prefer equality and symmetry. ${ }^{15}$ Females value cooperation because it involves a concern for others, selflessness, and a desire to be at one with others; however, males also value cooperation for males create relationships by doing things together. ${ }^{13,15}$

From the description of language used by males and females, it can be seen that some gamebased activities appeal more to males, ones competitive in nature, while others appeal to females, ones cooperative in nature. It can also be seen that game-based activities cooperative in nature can also appeal to males; therefore, cooperative activities are able to engage both genders. Engaging both genders is an important task to accomplish in regards to communication because it is important to discover a way to teach both genders effective communication skills for they are important in future careers. ${ }^{13}$ The goal of these game-based communication activities was to develop communication skills in both male and female students.

This study analyzes the role game-based pedagogy has on student perceptions of important aspects of communication. It also considers potential differences between male and female perceptions of these communication aspects. Game-based learning incorporates game design elements to non-game contexts, balancing subject matter and game play to help players engage in the information being presented. It allows students to learn while playing and makes it possible for students to perform tasks professional engineers may have while in an environment where it is safe to fail. ${ }^{16}$ Game-based learning allows students to explore the work environment, become accustomed to workplace expectations, and make mistakes that could potentially cost them their career had they actually been at work. This study will provide examples of gamebased learning that are relevant to developing engineering undergraduates' communication skills and preparing these students for the kind of communication that is expected in industry.

\section{Research Questions}

This study investigates students' perceptions of communication derived from their participation in game-based activities based on students' reflections. More specifically, this study asks: 
- How do games influence students' perceptions of skillsets that are important within written and oral communication?

- Is there a difference between male and female students' perceptions of skillsets that are important within written and oral communication?

\section{Methods}

During the spring 2015 semester at a large research university, 86 undergraduate sophomore level chemical engineering students - 55 males and 31 females - enrolled in a section of Introduction to Chemical Product Design. Communication topics covered in class included translating scientific literature for a target audience, presentation techniques and slide preparation, body language and nonverbal communication, email communication, and discussion techniques. This class included specific game-based activities focused on building communication skills including "ROYGBIV," "Mystery Liquid," and "Professional Slide." Students were evaluated on both their oral and written communication skills at the end of the semester through submission of a final written design report and infomercial. Evaluation of student outcomes between those taught without games (more traditional instruction) and those taught with games has been completed and demonstrated that students exposed to game-based learning methods had enhanced oral and written communication skills. ${ }^{17}$ The purpose of this study was to focus on students' perceptions of communication derived from their participation in these activities.

\section{Communication Games Overview}

"ROYGBIV" was meant to demonstrate to students that our perceptions of an image or interpretations of content can be very different from that of our audience. This game-based activity gave each student a card with a code and one piece of information on the bottom of the card as shown in Figure 1. They then had to use solely oral communication - no drawing or writing - to explain the symbols on their card and gather feedback on what their card was meant to represent. This meant that they had to listen closely to their peers to ensure that they were getting the description of a symbol they needed. They also had to be careful in how they described their symbol so that it would

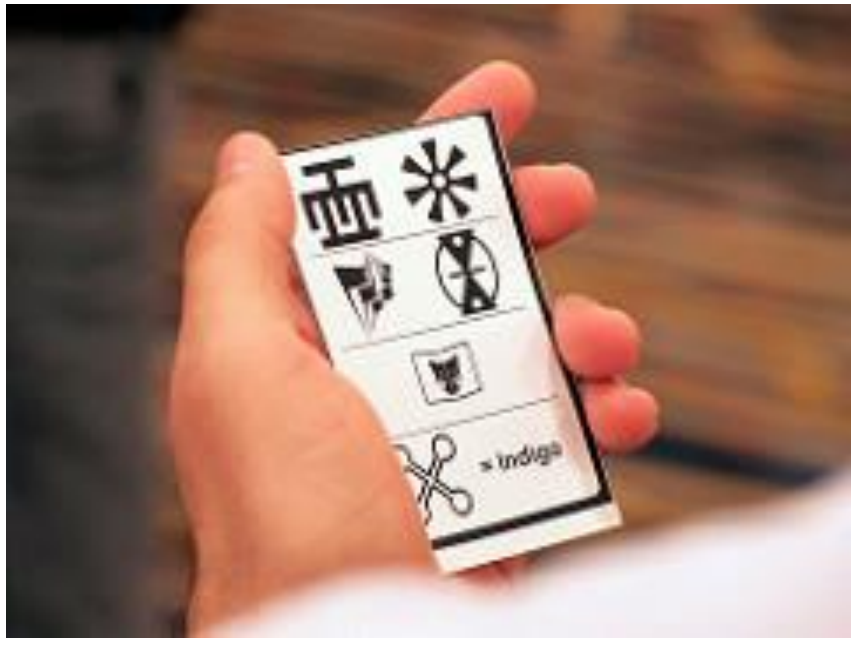

Figure 1. Sample ROYGBIV game card not be misinterpreted. To get the necessary information to solve their code, students needed to speak to a lot of different students in the class, not just their peer group as each student was only provided with the one piece of information at the bottom of their card. Once they had decoded their card, they then had to change the color of a square tile on the instructor's computer which allowed for verification as to whether the class had correctly decoded the message.

"Mystery Liquid" was meant to demonstrate to students how it is necessary to provide a lot of succinct information to the audience to ensure that they understand the product or process you are describing. Students were placed into teams where each group member inspected a different 
unknown liquid. After using touch, sight and smell to observe the liquid, they had to prepare a written description of the liquid and return with this information about their mystery liquid so the remainder of the group could correctly identify the liquid without ever seeing it. Students were instructed that once they had returned to their group they weren't allowed to speak or describe anything they had observed as their written description was to be the sole source of information for their group. By leaving out details, students could have misled their audience which would have led to broader miscommunication.

Finally, "Professional Slide" was meant to show students how difficult it can be to communicate information with limited space without alienating their audience. Groups of students acted as a company in distress that needed to explain to the public why a recall had been issued on their product. Within the class there were four different prompts provided to students groups environmental issues with a product, medical side effects, instability in a key component of their product, or dangerous manufacturing conditions. None of the student groups were aware of how many groups were working on the same prompt as themselves. Additionally, student groups were instructed that professional engineers from industry had been provided with the same set of prompts and had prepared slides that were to be added to the final slide deck that would be shown to the class although this wasn't the actual case. The purpose behind this deception was to enlist a competitive nature to the activity where each student group was striving to prepare the most professional slide that would be seen as good as if not better than what could be created by a professional in the industry. The culminating activity from this game-based exercise was for students to vote on which slide was the most professional looking for each prompt which resulted in them selecting one of their peer group's slide and an enriching discussion about why the particular slide selected was considered to be professional looking. This game-based activity was focused on being able to select the key information that was necessary for communicating the provided message while conveying trustworthiness and doing so in a professional manner.

Complete instructions for each of these games including materials needed, goals, and how to facilitate the game can be found in a games toolkit available online. ${ }^{18}$

\section{Communication Games Reflection Exercises}

To gauge students' perceptions of communication, reflection-based homework assignments for these game-based communication activities were given to students. The homework prompts included "What were the main takeaways that you got from this game-based activity in regards to your oral communication skills" for ROYGBIV, "How do you think this activity changed your approach to written communication" for Mystery Liquid, and "Reflect on how this experience contributed to your communication skill development" for the Professional Slide activity. The homework responses to these prompts were then content analyzed using a coding scheme for the reflections that was developed using a grounded, emergent qualitative analysis as described below.

\section{Student Reflection Analysis}

Thematic analysis is a method for identifying, analyzing, and reporting patterns or themes within data. A theme captures something important about the data in relation to the research question and represents some level of patterned response or meaning within the data set. ${ }^{19}$ There are two ways themes can be identified within a data set using thematic analysis - with an inductive or 
theoretical approach. An inductive approach means the themes identified are strongly linked to the data themselves; meaning inductive analysis is a process of coding the data without trying to fit it into a pre-existing framework or analytic preconception. A specific research question can evolve through the coding process of an inductive approach. A theoretical approach, in contrast, is driven by the researcher's theoretical or analytic interest in the area, coding for a specific research question and focusing on a specific feature in coding the data. ${ }^{19}$ An inductive thematic analysis was conducted in this study. Homework responses were collected, read and re-read to identify patterns related to the takeaways from the game-based communication activities (shown in Table 1). Patterns were linked to themes as the analysts understood the homework responses to represent. Themes captured the struggles of communication that students encountered and knowledge students gained while participating in the game-based communication activities. While completing homework assignments, the majority of students addressed the same struggles they had based on the game-based activity, the same key takeaways, and the same contributions to the development of their communication skills; therefore, these common responses became the themes of this study.

Table 1: Framework of themes developed from student homework responses

\begin{tabular}{|c|c|c|}
\hline Category & Sub-category & Description \\
\hline \multirow[t]{3}{*}{ Difficulties } & Misleading & $\begin{array}{l}\text { Information provided in communication may steer } \\
\text { audience to a specific thought that doesn't match the } \\
\text { desired goal of communication }\end{array}$ \\
\hline & Biases & $\begin{array}{l}\text { Audience may have past experiences that influence } \\
\text { how they perceive information; importance in } \\
\text { identifying biases when preparing communications }\end{array}$ \\
\hline & $\begin{array}{l}\text { Stepping Out of } \\
\text { Comfort Zone }\end{array}$ & $\begin{array}{l}\text { Specific to oral communication the need to speak to } \\
\text { individuals that aren't known by the individual, getting } \\
\text { feedback on ideas, doing more than expected }\end{array}$ \\
\hline \multirow[t]{3}{*}{$\begin{array}{l}\text { Audience } \\
\text { Perception }\end{array}$} & Wording & $\begin{array}{l}\text { Types of descriptions that are used in communication } \\
\text { influencing the perception of the final product }\end{array}$ \\
\hline & $\begin{array}{l}\text { Understanding/ } \\
\text { Listening }\end{array}$ & $\begin{array}{l}\text { Person's perspective is not always that of the audience; } \\
\text { need to reflect on target audience and their background } \\
\text { to help encourage more effective communication }\end{array}$ \\
\hline & Misinterpretation & $\begin{array}{l}\text { Thoughts conveyed by speaker or writer are not } \\
\text { interpreted as intended }\end{array}$ \\
\hline \multirow[t]{4}{*}{ Approach } & Framing & $\begin{array}{l}\text { How to set up the piece of communication and } \\
\text { determine what should be included and what may not } \\
\text { be necessary, use comparisons, starting from shared } \\
\text { experiences }\end{array}$ \\
\hline & Organization & $\begin{array}{l}\text { The method used to prepare the piece of } \\
\text { communication, how many sections or bullet points, } \\
\text { any common themes grouped together }\end{array}$ \\
\hline & Detail & $\begin{array}{l}\text { Amount of detail that is included within } \\
\text { communication piece, length of the piece and its impact } \\
\text { on the ability to convey the correct information }\end{array}$ \\
\hline & Presentation & $\begin{array}{l}\text { Clarity of the final piece of communication, level of } \\
\text { professionalism }\end{array}$ \\
\hline
\end{tabular}


For example, the following homework responses were coded as such:

Table 2: Example response from the ROYGBIV game-based activity

\begin{tabular}{|c|c|c|}
\hline $\begin{array}{l}\text { Game-based } \\
\text { Activity }\end{array}$ & Text Entry & Theme(s) \\
\hline ROYGBIV & $\begin{array}{l}\text { Oral communication skills are just as } \\
\text { difficult as written skills to work on. I think } \\
\text { it was a lot harder than it originally seemed. I } \\
\text { learned that it is important to talk to different } \\
\text { people because they may know things I do } \\
\text { not. Also I learned that being descriptive will } \\
\text { help others understand you if you are } \\
\text { describing something. }\end{array}$ & $\begin{array}{l}\text { 1. } \begin{array}{l}\text { Difficulties - stepping } \\
\text { out of comfort zone }\}\end{array} \\
\text { 2. } \begin{array}{l}\text { Audience perception }- \\
\text { wording }\end{array}\end{array}$ \\
\hline
\end{tabular}

The response shown in Table 2 was coded to contain the stepping out of comfort zone theme under the difficulties category and the wording theme under the audience perception category. The part of the response that states "it is important to talk to different people because they may know things I do not" shows the stepping out of comfort zone theme. The analysts took "different" people as people the student did not necessarily know or people that were not part of the student's immediate peer group. This student realized he/she must speak to individuals that aren't known by him/her to acquire new information. The wording theme can be seen by the statement "being descriptive will help others understand." This response directly shows the student thought about the types of descriptions that influence the audience's understanding of the final product.

Table 3: Example response from the Mystery Liquid game-based activity

\begin{tabular}{|c|c|c|}
\hline $\begin{array}{l}\text { Game-based } \\
\text { Activity }\end{array}$ & Text Entry & Theme(s) \\
\hline Mystery Liquid & $\begin{array}{l}\text { I think that this activity clearly showed that } \\
\text { written communication can easily be } \\
\text { misinterpreted by others when descriptions } \\
\text { are being made through a biased filter. Being } \\
\text { able to provide specific details without } \\
\text { directly making an assumption in these } \\
\text { descriptions was vital to conveying useful } \\
\text { information for everyone to consider. }\end{array}$ & $\begin{array}{ll}\text { 1. } & \text { \{Audience perception - } \\
\text { misinterpretation }\} \\
\text { 2. } \\
\text { 3. } \text { \{Difficulties - biases }\} \\
\text { Approach - detail }\}\end{array}$ \\
\hline
\end{tabular}

The response shown in Table 3 was coded to contain the misinterpretation theme under the audience perception category, the biases theme under the difficulties category, and the detail theme under the approach category. The part of the response that states "written communication can easily be misinterpreted by others" shows the misinterpretation theme. This student recognized that thoughts of the writer are not always interpreted as intended. The part of the response that states "when descriptions are being made through a biased filter" and "without making an assumption" shows the biases theme. The audience or the writer may have past experiences that influence how they perceive or convey information, and this student reflected on this fact in his/her homework response. Finally, the part of the response that states "being able to 
provide specific details ... to conveying useful information for everyone to consider" shows the detail theme. This student reflected on the amount of detail needed and its impact on the ability to convey useful information which is what the detail theme aims to address.

Table 4: Example of a student response coded with no themes

\begin{tabular}{|l|l|l|}
\hline $\begin{array}{l}\text { Game-based } \\
\text { Activity }\end{array}$ & Text Entry & Theme(s) \\
\hline $\begin{array}{l}\text { Professional } \\
\text { Slide }\end{array}$ & $\begin{array}{l}\text { This process made it painfully evident how } \\
\text { vital those jobs and skills are. I may not have } \\
\text { benefitted a significant amount directly, but } \\
\text { gaining an understanding of how vital these } \\
\text { skills are gave me a deeper appreciation of } \\
\text { appropriate communication skills. }\end{array}$ & \{None \\
\hline
\end{tabular}

The response in Table 4 was coded to have no themes present. Though this student's response is a reflection of the "Professional Slide" gamed-based communication activity, no part of the response corresponds to the main themes that were identified in the content analysis of student responses.

The themes developed in this study or aspects of them can be seen in the 16 communication skills rated by engineers as important as shown by a field study conducted by Corrello. ${ }^{20}$ Listening is directly stated in this list, along with giving feedback, routine information exchange, and persuading. Giving feedback, routine information exchange, and persuading all contain aspects of the wording, framing, organization, detail, and presentation themes while trying to avoid misleading an audience or having an audience misinterpret the feedback or data. These aspects can be seen in communication events such as the types of descriptions to use when giving a co-worker feedback on his or her presentation, what information to include and how much detail to provide when persuading business representatives to invest in an idea, or how many slides to include, if bullet points should be used, and the overall professional look of a presentation wrapping up the end of a project. Corello also talks about communication apprehension which is the level of fear or anxiety associated with real or anticipated communication with another person or group of people. ${ }^{20}$ Communication apprehension has aspects of the stepping out of comfort zone theme developed in this study.

Training on coding the student responses was performed using 10 student entries, and the remaining dataset for analysis contained 237 individual responses. Two analysts content analyzed all homework responses according to the framework shown in Table 1. Inter-rater reliability between coders was assessed using Cohen's Kappa. An inter-rater reliability of 0.641, 0.647, and 0.597 for the "Professional Slide," "ROYGBIV," and "Mystery Liquid" respectively was obtained, reflecting a fair level of agreement. ${ }^{21}$ The most prevalent themes for each gamebased activity were identified and are summarized in the results and discussion section. Differences in prevalent themes between students of different genders were also analyzed. 


\section{Results and Discussion}

This study attempted to understand how students were reflecting on game-based communication activities by answering how do games influence students' perceptions of skillsets that are important within written and oral communication?

As previously mentioned, each game-based communication activity focused on different aspects of communication that students had the opportunity to reflect on after participating in the gamebased activity. The top themes from each of the game-based communication activity reflections are summarized below.

The top three themes for the "ROYGBIV" communication game-based activity were understanding/listening [33], wording [26], and stepping out of comfort zone [26]. The total number of student responses including these elements is shown in brackets. Student responses ranged from 4 for the misinterpretation theme to 33 reflecting the understanding/listening theme. There was a total of 84 student responses for this game-based activity and a total of 157 counts of themes found in these responses. The understanding/listening theme identifies that a speaker's perspective is not always that of the audience, so the speaker needs to reflect on the background of the target audience to ensure effective communication occurs. In this game-based activity, students needed to listen closely to their peers as well as make sure they understood their audience to ensure they were getting and giving the correct description of the symbol. For example, as was shown in Figure 1 in the Communication Games Overview section, students may describe the symbol in the second row, first column as a series of mountain peaks or as a geometric pattern. They needed to be able to reflect on their audience and then look at their card to determine if there was perhaps multiple ways to describe a specific symbol. Students needed to effectively communicate to decode the symbols on their cards and hence their reflections demonstrated that this game-based activity reinforced their need to think about audience as part of communicating. The wording theme identifies descriptions that are used to make certain the audience understands the final product. Students needed to be careful in how they described their symbol so that it would not be misinterpreted to their peers. Students carefully choosing the descriptions used to describe their symbol demonstrated the use of the wording theme. Finally, the stepping out of comfort zone theme identifies doing more than expected to get feedback on ideas or obtain new information. Talking to individuals not known to the speaker would be considered doing more than expected. Students needed to talk to many other peers to decode their symbol, most of whom they had never talked to or were not in their immediate peer group. Students "stepped out of their comfort zones" to acquire different information needed to decode the symbols on their cards and therefore practiced the stepping out of comfort zone theme.

The top three themes for the "Mystery Liquid" communication game-based activity were detail [44], wording [30], and biases [28]. The responses ranged from 1 including the organization theme to 44 reflecting the detail theme. There was a total of 83 student responses for this gamebased activity and a total of 186 counts of themes found in the responses. The detail theme identifies the need to include specifics in a piece of communication to have the ability to convey the correct information as well as acknowledges the length of the piece. This game-based activity was meant to show students they needed to provide concise information to the audience to ensure they understood what was trying to be explained to them. It was clear from their reflections that after participating in the game-based activity they had a better concept of how much detail 
should go into written descriptions and that sometimes more can be better depending on the circumstances. For instance, only providing 1 or 2 words to describe their assigned mystery liquid wouldn't be sufficient to allow their team the opportunity to correctly identify the liquid they were assigned. Students also better understood the types of descriptions needed and how these descriptions influence the audience's perception of the final product by the presence of the wording theme. For example, if students were describing dishwashing liquid, they would use words to describe the smell, the color, the viscosity, if bubbles were present, etc. It was clear from student reflections that they better understood what kind of descriptors to use when describing something their audience had never before seen. This game-based communication activity also showed students it was important to only convey the information that was given and to not introduce their perception of the identity of the liquid. By inserting their own perceptions, students introduced bias, making it difficult for the audience to see past the bias. An example where this occurred was when students wrote Sprite or Sierra Mist as their description of the mystery liquid not providing their team with any opportunity to identify any other liquid. In this case, the liquid turned out to be lemon water which made the students realize that their perception isn't always correct and they should ensure that they provide an unbiased presentation of what they are asked to describe.

Finally, the top three themes for the "Professional Slide" game-based communication activity were framing [39], understanding/listening [29], and presentation [16]. The responses ranged from 2 including the misinterpretation theme and 4 including no theme to 39 reflecting the framing theme. There was a total of 80 student responses for this game-based activity and a total of 122 counts of themes found in these responses. The framing theme identifies how to set up and what should be included in a communication piece while the presentation theme addresses the need for clarity and professionalism in the final piece of communication. This game-based activity was meant to show students how to communicate information in a limited amount of space without alienating their audience. Its focus was being able to select key information to get the point across in a professional manner, without causing the audience distress. For example, students who received the prompt that their product was resulting in adverse medical side effects had to decide if they wanted to present all the medical side effects to the public, side effects that were the most critical, or the side effects that would not cause the audience to panic and if they should explain to the audience what these side effects entailed. Students also needed to decide what their company was going to do. Would they tell the public a recall was being issued and that they are removing their products from stores or tell the public the problem is being resolved and that they are keeping stores stocked? Would customers respect their professional decisions and understand their actions or would their customers think they were unsafe and use another brand? From reflections, it was clear students thought about what was needed to inform the public and what might have just been supplemental information. It was also clear students understood their audience must understand exactly what was happening in order to avoid mass hysteria, therefore their slide had to provide clarity. In order to understand what information was needed and how to present this information in a clear way, students needed to reflect on their target audience. For example, the student group whose product resulted in side effects knows the medical terminology of the side effects but who are they presenting to - medical professionals, engineers, or the general public? Will their audience know and understand these medical terms or should the company present them in layman's terms? Students reflected the importance of conveying information in a way the "common man" would understand it. 
Themes within student reflections of these game-based activities aligned with the key takeaways of the games, showing that students understood the communication skills needed to succeed in these game-based activities. Self-reflection may aid in carry-over of course material to outside of the classroom. ${ }^{22}$ Therefore, students should be able to translate these communication skills to other contexts, specifically industry. The teaching delivery strategy for workplace skills is not that of a traditional classroom but one that includes active and cooperative learning which is how this class is arranged. ${ }^{23}$ A comprehensive survey conducted by Mishra and Foster identified 250 distinct claims about games for learning. Using grounded theory analysis, these claims were categorized under five themes: cognitive skills, practical skills, motivation, social skills, and physiological. Examination of their findings revealed that there is a general consensus: games can lead to changes in attitudes, behaviors, and skills. ${ }^{16}$ The first theme under the social skills category was communication; therefore, according to Mishra and Foster's analysis, games can change students' attitudes about communication and their communication skills. The conclusion found by Mishra and Foster supports what is being hypothesized in this study. Kirriemuir and McFarlane also found that playing games can support valuable skill development such as strategic thinking, planning, communication, negotiating skills, group decision making, and data handling. ${ }^{16}$ Other studies completed by Macy, Squires, and Barton and Dede have concluded that game-based learning has enabled a merging of play and learning which can lead to staged learning opportunities that replicate real life and the transfer of knowledge learned from one situation to another. ${ }^{16}$ These studies support game-based learning having the capability to not only allow students to develop communication skills but also learn the ability to transfer these skills to other contexts.

After determining how games influence students' perceptions of important communication skills overall, this study asked is there a difference between male and female students' perceptions of skillsets that are important within written and oral communication?

To determine if there was any difference in males and females perceptions, the top themes that males and females reflected upon were compared for each game-based communication activity and the results of this analysis can be seen in Table 5 .

Table 5: Top themes from males and females for each game-based activity

\begin{tabular}{|l|c|c|c|c|c|}
\hline \multirow{4}{*}{ ROYGBIV } & First & $\begin{array}{c}\text { Male } \\
(55 \text { students total })\end{array}$ & $\begin{array}{c}\% \text { of total } \\
\text { male } \\
\text { students }\end{array}$ & $\begin{array}{c}\text { Female } \\
\text { (31 students total) }\end{array}$ & $\begin{array}{c}\% \text { of total } \\
\text { female } \\
\text { students }\end{array}$ \\
\cline { 2 - 6 } & Second & Wording [15] & $27 \%$ & $\begin{array}{c}\text { Stepping out of comfort } \\
\text { zone [11] }\end{array}$ & $35 \%$ \\
\cline { 2 - 6 } & Third & $\begin{array}{c}\text { Stepping out of } \\
\text { comfort zone [15] }\end{array}$ & $27 \%$ & $\begin{array}{c}\text { Understanding/ } \\
\text { listening [9] }\end{array}$ & $29 \%$ \\
\hline \multirow{2}{*}{$\begin{array}{l}\text { Mystery } \\
\text { Liquid }\end{array}$} & First & Detail [31] & $56 \%$ & Detail [13] & $42 \%$ \\
\cline { 2 - 6 } & Second & Wording [17] & $31 \%$ & Understanding/listening & $42 \%$ \\
& Third & Biases [17] & $31 \%$ & Wording [13] & $42 \%$ \\
\cline { 2 - 6 }
\end{tabular}




\begin{tabular}{|l|c|c|c|c|c|}
\hline & & $\begin{array}{c}\text { Male } \\
\text { (55 students total) }\end{array}$ & $\begin{array}{c}\% \text { of total } \\
\text { male } \\
\text { students }\end{array}$ & $\begin{array}{c}\text { Female } \\
\text { (31 students total) }\end{array}$ & $\begin{array}{c}\% \text { of total } \\
\text { female } \\
\text { students }\end{array}$ \\
\hline $\begin{array}{l}\text { Professional } \\
\text { Slide }\end{array}$ & First & Framing [22] & $40 \%$ & Framing [17] & $55 \%$ \\
\cline { 2 - 6 } & Second & $\begin{array}{c}\text { Understanding/ } \\
\text { listening [19] }\end{array}$ & $35 \%$ & $\begin{array}{c}\text { Understanding/listening } \\
{[10]}\end{array}$ & $32 \%$ \\
\cline { 2 - 6 } & Third & Presentation [11] & $20 \%$ & $\begin{array}{c}\text { Tie - Wording [7] } \\
\text { Detail [7] }\end{array}$ & $23 \%$ \\
\hline
\end{tabular}

Although as noted in Table 5, there is a difference in ranking of the different themes for some of the game-based activities it was found that there was no statistical differences between the proportions of females vs. males that selected any one specific theme based upon a z-test of proportions.

The prevalent themes reflected by males and females for the "ROYGBIV" game-based activity are identical; the only difference is in the ordering of the themes - the number one theme for males was understanding/listening while the number one theme for females was wording. This similarity in themes but difference in ranking may mean males and females put different priorities on certain aspects of communication but overall have a consensus about what is important. This difference in priorities may come from the fact males and females view the purpose of conversations differently.

Males and females agreed that the detail theme was the most important theme in the "Mystery Liquid" game-based communication activity; however, different priorities are placed on the wording theme. Males took the perspective that biases were important in this game-based communication activity while females took the perspective of understanding/listening. Both themes acknowledge the need to know the background of the audience; however, during the activity, males may have had difficulties with biases clouding their perception of the liquid and therefore the audience's perception whereas females may have acknowledged their audience did not have the same perspective as they had for their audience did not see the liquid, and therefore, to promote effective communication, females realized what was necessary for an appropriate explanation of the liquid. Another hypothesis is females may have also had the same difficulties with biases as males did, but females reflected the understanding/listening theme as a way to combat the biases they encountered.

For the "Professional Slide" game-based activity, the top three themes males reflected were framing, understanding/listening, and presentation while the top three themes females reflected were framing, understanding/listening, and a tie between detail and wording for the third most prevalent theme. For this game-based communication activity, males and females agreed framing and understanding/listening were the most important communication aspects to succeed in this game-based activity. Because the final top theme between genders was different, this may mean males and females took a different perspective when reflecting on this game-based activity. Males may have looked at the overall slide - the level of clarity and professionalism it brought; however, females may have looked at the minute details and certain descriptions that were needed in the slide to provide clarity and professionalism, explaining males reflecting on the 
presentation theme while females reflected on the detail and wording themes as their third top theme. Again, this difference in perspective may come from males and females viewing the purpose of communication differently.

Overall, there was very little variation in the top three themes between male and female communication game-based activity reflections. This could be indicative that the game-based activities selected were able to equally apply to both genders. These particular game-based activities were also collaborative in nature which has been shown to appeal to both genders. ${ }^{13,15}$ Communication within the context of these particular activities may also be perceived similarly by both genders, explaining why both genders, for the most part, reflected on the same themes for all of the game-based communication activities.

\section{Study Limitations}

This study was conducted over a single semester with one section of an Introduction to Chemical Product Design Class containing 86 sophomore level chemical engineering students. This class was designed to include many game-based activities. Because of these factors, it is uncertain how transferrable these results may be to other classroom environments, and these results may not be generalizable to other student populations. This class contained more males than females; therefore, male reflections had more of an impact on the overall top three themes identified where there was a difference in perceptions between males and females.

\section{Conclusions}

Effective communication is an important aspect to any field, including engineering. Without proficient communication skills, catastrophic events can occur and a successful industry career is unlikely. However, many engineering graduates do not have the communication skills to meet the needs of industry employers. Engineering education has attempted to combat this issue, but the gap between employer needs and student abilities still exists. To understand student perceptions of communication through participation in game-based activities, this study asked students to reflect on the game-based activities they participated in and how they contributed to their communication skill development. Across all game-based activities, understanding/listening and wording were the most prevalent themes; females reflected these themes to such a degree that they were in the top three themes for all game-based activities; these themes were in the top three themes for two game-based activities for males. These common themes reinforce students recognizing how these skills sets are critical to their communication practice, making gamebased learning a potential bridge between students' skills and employers' needs in regards to communication. In fact, employers are using games to judge the quality of a candidate's professional skills such as communication. ${ }^{24}$ As game-based learning is experiential, students learn by doing and therefore have a higher likelihood of being able to transfer the skillsets learned into different contexts. Critical reflection is needed after these game-based activities to build student learning - to reinforce and reiterate what was learned so when students enter industry, they can remember and practice the skills that were developed in college.

This study also examined differences in communication game-based activity reflections between males and females. There was very little variation between genders in their reflections, meaning game-based learning may have the ability to impact male and female perceptions similarly. It was determined that the priorities and perspectives of certain communication aspects may be 
different between males and females, which may stem from each gender viewing the purpose of communication differently. However, there was a consensus between genders about the overall importance of certain aspects within each game-based communication activity. Because of this consensus and the alignment of reflection themes and desired outcomes of the game-based communication activities, game-based learning followed by critical reflections may be a suitable pedagogical tool for the development of communication skills in chemical engineering undergraduates.

\section{Acknowledgements}

The authors would like to acknowledge funding that was provided by the Engineering Information Foundation (EIF) for this study. They would also like to thank Pete Vigeant, who designed the communication games used within this study and provided support for their classroom implementations.

\section{References}

1. "3 Engineering Disasters That Were the Results of Miscommunication." AUCOTEC. N.p., 31 May 2016. Web. 19 Nov. 2016.

2. Lloyd, R. "Metric Mishap Caused Loss of NASA Orbiter." CNN 30 September 1999: CNN. Web. 19 Nov. 2016

3. Dickerson, K. "8 Tragic Miscalculations and Miscommunications." Business Insider. N.p., 20 Oct. 2013. Web. 19 Nov. 2016

4. Darling, A. L., and D. P. Dannels. "Practicing Engineers Talk about the Importance of Talk: A Report on the Role of Oral Communication in the Workplace." Communication Education 52.1 (2003): 1-16.

5. Vest, D., M. Long, and T. Anderson. "Electrical Engineers' Perceptions of Communication Training and Their Recommendations for Curricular Change: Results of a National Survey." IEEE Transactions on Professional Communication 39.1 (1996): 38-42.

6. Winsor, D. A. "Genre and Activity Systems the Role of Documentation in Maintaining and Changing Engineering Activity Systems.” Written Communication 16.2 (1999): 200-224.

7. Sageev, P. and C. J. Romanowski. "A Message from Recent Engineering Graduates in the Workplace: Results of a Survey on Technical Communication Skills." Journal of Engineering Education 90.4 (2001): 685-693.

8. Evans, D. L., G.C. Beakley, P.E. Crouch, and G.T. Yamaguchi. "Attributes of Engineering Graduates and Their Impact on Curriculum Design.” Journal of Engineering Education 82.4 (1993): 203-211.

9. Brunhaver, S. R., R. F. Korte, S. R. Barley, and S. D. Sheppard. "Bridging the Gaps between Engineering Education and Practice." Engineering in a Global Economy. Cambridge, MA: National Bureau of Economic Research. Manuscript

10. Itani, M. \& I. Srour. "Engineering Students' Perception of Soft Skills, Industry Expectations, and Career Aspirations." Journal of Professional Issues in Engineering Education and Practice 142.1 (2016): n. pag.

11. Kedrowicz, A. A. and J. L. Taylor. "Engineering Communication and the Global Workplace Preparing Professionals and Global Citizens." Connexions International Professional Communication Journal. 1.2 (2013): 81-105.

12. Fleury, A. "Liberal Education and Communication against the Disciplines." Communication Education 54.1 (2005): 72-79.

13. Merchant, K. "How Men and Women Differ: Gender Differences in Communication Styles, Influence Tactics, and Leadership Styles." Claremont Colleges Senior Thesis. 2012.

14. Gray, J. Men are from Mars, Women are from Venus: a Practical Guide for Improving Communication and Getting What You Want in a Relationship. New York: HarperCollins, 1992. 
15. Tannen, D. You Just Don't Understand: Women and Men in Conversation. New York: Ballantine Books, 1990.

16. Ifenthaler, D., D. Eseryel, and X. Ge. Assessment in Game-Based Learning. New York: Springer, 2012.

17. Bodnar, C.A., and R.M. Clark. "Can Game-Based Learning Enhance Engineering Communication Skills?" IEEE Transactions on Professional Communication 60.1 (2017): 24-41.

18. Epicenter Blog, Innovation and entrepreneurship games. 2015. [Online]. Available: http://epicenter.stanford.edu/resource/innovation-and-entrepreneurship-games

19. Virginia, B. and V. Clarke. "Using Thematic Analysis in Psychology." Qualitative Research in Psychology 3.2 (2006): 77-101.

20. Corrello, M. L. "Communication and the Engineering Profession: a Field Study." U.K.: College of Communication.

21. Norusis, M. SPSS 14.0 Statistical Procedures Companion. Upper Saddle River, NJ: Prentice Hall, pp. 152, pp. $183,2005$.

22. Mineart, K. P. and M. Cooper. "Improving Student Technical Communication via Self Reflection." ASEE 2016 Annual Conference, June 26-29th, 2016. New Orleans, Louisiana. 2016.

23. Matusovich, H. M., M. C. Paretti, A. M. Motto, and K. J. Cross. "Understanding Faculty and Student Beliefs about Teamwork and Communication Skills." ASEE 2012 Annual Conference, June 10-13th, 2012. San Antonio, Texas. 2012.

24. Sambamurthy, N. and M. F. Cox. "Developing a Behavior-Based Rubric for Assessing Professional Skills during Hiring." ASEE 2016 Annual Conference, June 26-29th, 2016. New Orleans, Louisiana. 2016. 